\title{
INCIDENCIA SOCIOECÓNOMICA DEL CULTIVO DE PALMA AFRICANA EN EL MUNICIPIO DE PUERTO GAITÁN- DEPARTAMENTO DEL META Y SU EVOLUCIÓN EN EL PERIÓDO
} (1991-2017)

\section{Socio economic impact of the growth of African palm trees in the municipality of Puerto Gaitán-Meta and its evolution during the period (1991-2017)}

\author{
Adriana Marcela Cubides Peña \\ Ruddy Andrea Rivera Luque \\ Director: Dr. Oscar Luis Pyszczek \\ Programa de Ingeniería Geográfica y Ambiental. Facultad de Ingeniería. \\ Universidad de Ciencias Aplicadas y Ambientales (UDCA)-Colombia
}

http://dx.doi.org/10.30972/geo.15292903

\section{RESUMEN}

El presente trabajo de investigación pretende indagar las transformaciones socioeconómicas derivadas del desarrollo del cultivo de Palma Africana, basado en tres aspectos principales: la tenencia de la tierra, competencia entre actividades económicas con repercusión en la población, y la expansión no planificada; mediante el análisis de la evolución del cultivo de palma en el municipio de Puerto Gaitán para el periodo de 1991 a 2017. Dado que este municipio posee una gran participación en la producción palmera del Departamento del Meta, ha tenido una evolución vertiginosa en la última década, generando diferencias sociales y económicas notables en los últimos 30 años.

\section{PALABRAS CLAVES}

Palma Africana, Incidencia socioeconómica, expansión no planificada, tenencia de la tierra, competencia económica.

\begin{abstract}
The present research work aims to investigate the socio-economic transformations resulting from the development of the cultivation of Palm, based on three main aspects: the tenure of the land, competition between economic activities with impact in the population and the expansion not planned, through the analysis of the evolution of the palm cultivation in the municipality of Puerto Gaitán for the period of 1991 to 2017. Given that this municipality has a large participation in the production of Palm tree with the Department of Meta, has had a dizzying evolution in the last decade, generating social and economic significant differences when compared over the last 30 years.
\end{abstract}

\section{KEY WORDS}

Palm oil, socio-economic incidence, unplanned expansion, land, economic competition.

Publicado en formato digital Adriana M. Cubides Peña, Ruddy A. Rivera Luque. Director: Dr. Oscar Luis Pyszczek. INCIDENCIA SOCIOECÓNOMICA DEL CULTIVO DE PALMA AFRICANA EN EL MUNICIPIO DE PUERTO GAITÁN- DEPARTAMENTO DEL META Y SU EVOLUCIÓN EN EL PERIÓDO (1991-2017). Revista Geográfica Digital. IGUNNE. Facultad de Humanidades. UNNE. Año 15. № 29. Enero - Junio 2018. ISSN 1668-5180 Resistencia, Chaco.

En: http://hum.unne.edu.ar/revistas/geoweb/default.htm - http://dx.doi.org/10.30972/geo.15292903 
Revista Geográfica Digital. IGUNNE. Facultad de Humanidades. UNNE. Año 15. № 29.

Enero - Junio 2018. ISSN 1668-5180 Resistencia, Chaco

\section{INTRODUCCIÓN}

A partir del crecimiento de los monocultivos y el desarrollo de las actividades agrícolas a nivel mundial, los cultivos de palma se han posicionado como una de las prácticas agrícolas en crecimiento. Desde los años noventa el área ocupada por el cultivo de palma de aceite se ha expandido alrededor de un $43 \%$ a nivel mundial; impulsada principalmente por la demanda de India, China y la Unión Europea.

La palma de aceite está presente en cuatro zonas de Colombia: Norte, Oriental, Central y Suroccidental, que abarcan 122 municipios en 19 departamentos ${ }^{1}$ alrededor del país, siendo su área sembrada de 500.000 hectáreas aproximadamente. La palmicultura es una de las actividades agrícolas más prometedoras como eje de desarrollo nacional (Cenipalma, 2015). En Colombia, los cuestionamientos relacionados al cultivo de palma se han concentrado en conflictos de tierras en áreas puntuales; sin embargo, el país cuenta con una amplia disponibilidad de áreas para aumentar el cultivo sin sacrificar bosques primarios. El Departamento del Meta abarca 3 municipios con la mayor productividad de aceite de palma del departamento; correspondiente a San Martin, Acacias y Puerto Gaitán.

En el municipio de Puerto Gaitán, el sector palmero se consolida como una de las actividades agrícolas con mayor crecimiento en la última década (EOT, 2012: 8). No obstante, si se analiza las contribuciones de las actividades económicas al presupuesto municipal, la extracción y procesamiento del petróleo es el mayor generador de recursos para este municipio, conformando aproximadamente el 90\% del presupuesto anual, entre los años 2007 al 2014.

En ese sentido el municipio ha realizado esfuerzos dirigidos a diversificar sus actividades económicas y ha comenzado a propiciar el cultivo de palma africana; actividad que se ejecuta desde los eslabones agrícolas (siembra y cosecha), industriales (extracción y procesamiento) y comercialización del producto final (aceite de palma). La irrupción del cultivo de palma africana ha propiciado la ocurrencia de dinámicas y transformaciones de orden socioeconómico en el ente territorial, fundamentalmente enfocados en la tenencia de la tierra (aumento de las áreas destinadas a uso agrícola), la competencia de actividades económicas (ligadas por una parte al proceso de extracción de hidrocarburos y por otra a la agricultura de gran escala), y la expansión no planificada del cultivo de palma africana. Las variables antes mencionadas, si bien no representan aún una problemática acuciante en el municipio, lo serán en corto plazo, por lo que resulta de suma importancia proponer líneas de acción que permitan un desarrollo sostenible y sustentable para el municipio, en función de la protección ambiental, la inclusión de la población en las actividades económicas y la ejecución de buenas prácticas comunales

\section{ÁREA DE ESTUDIO}

Puerto Gaitán es el cuarto municipio más grande de Colombia y primero del Departamento del Meta. Se encuentra comprendido entre las coordenadas de: $3^{\circ} 05^{\prime}$ a $4^{\circ} 08^{\prime}$ latitud Norte y $71^{\circ}$ $05^{\prime}$ a $72^{\circ} 30^{\prime}$ longitud Oeste.

\footnotetext{
${ }^{1}$ La unidad administrativa denominada "Departamento" en Colombia, es equivalente a "Provincia" en el caso de la República Argentina.
}

Publicado en formato digital Adriana M. Cubides Peña, Ruddy A. Rivera Luque. Director: Dr. Oscar Luis Pyszczek. INCIDENCIA SOCIOECÓNOMICA DEL CULTIVO DE PALMA AFRICANA EN EL MUNICIPIO DE PUERTO GAITÁN- DEPARTAMENTO DEL META Y SU EVOLUCIÓN EN EL PERIÓDO (1991-2017). Revista Geográfica Digital. IGUNNE. Facultad de Humanidades. UNNE. Año 15. № 29. Enero - Junio 2018. ISSN 1668-5180 Resistencia, Chaco. 
Con una superficie de $17.499 \mathrm{~km}^{2}$, Puerto Gaitán limita al Norte con el Departamento del Casanare; al Sur con los Municipios de Mapiripan y San Martín; al Este con el Departamento del Vichada y al Oeste con los Municipios de Puerto López y San Martín. Las características naturales y la misma localización geográfica del municipio lo sitúan en condiciones estratégicas privilegiadas en el contexto colombiano. El reconocido potencial agrícola de los suelos de Puerto Gaitán ha sido la base sobre la cual se han generado grandes proyectos agroindustriales en cultivos de arroz, maíz, soya, plátano, yuca, palma africana, caucho, pino y ganadería de carne, cría y levante. (Alcaldía de Puerto Gaitán, 2016)

Figura 1. Localización geográfica Municipio de Puerto Gaitán-Meta

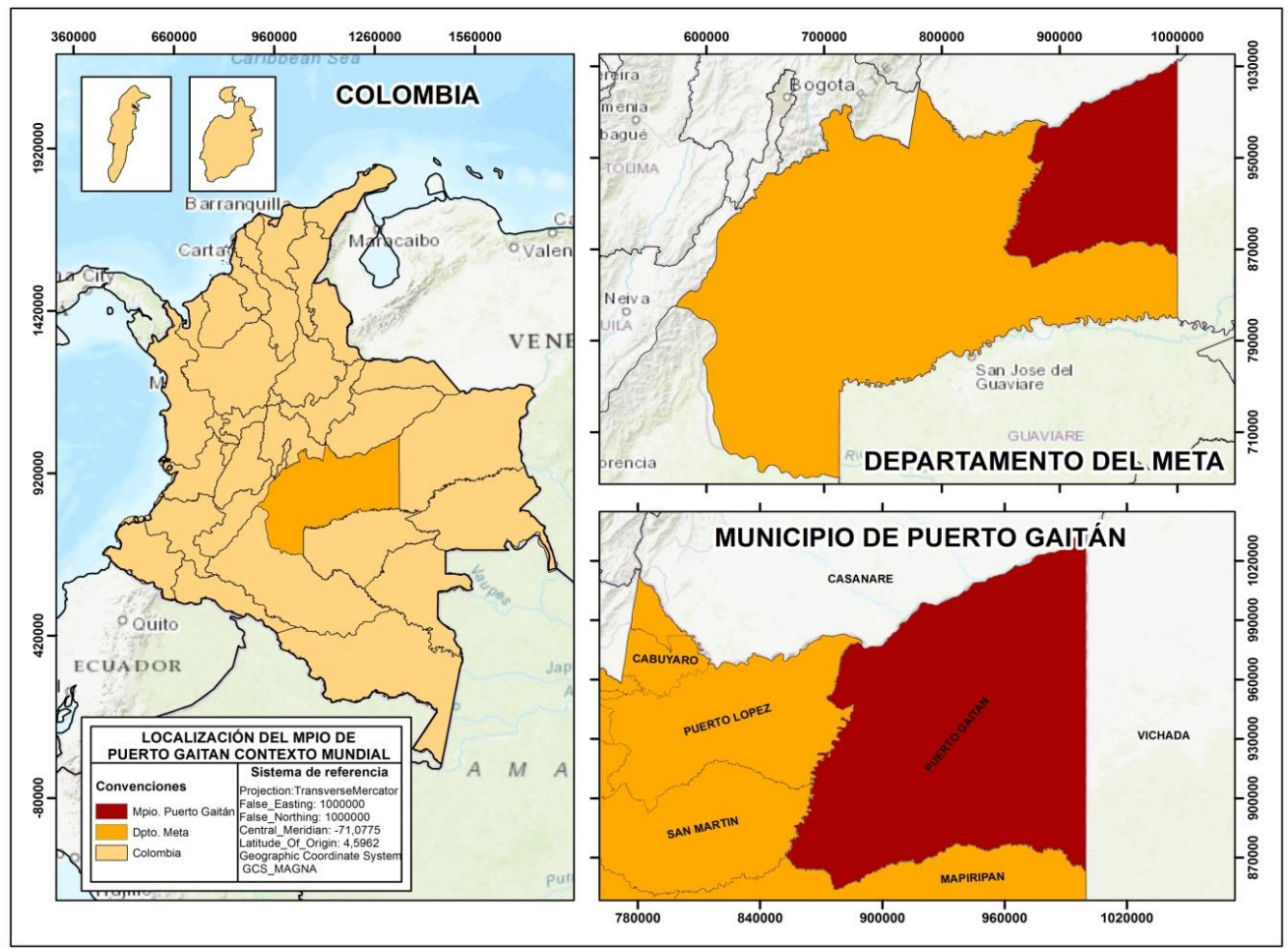

Fuente: Elaboración propia con base en información del Sistema de Información Geográfica para la Planeación y el Ordenamiento Territorial Nacional (SIGOT)

\section{METODOLOGÍA}

La metodología contempla una aproximación de tipo cuali-cuantitativo expresada en la siguiente tabla de matriz metodológica:

Publicado en formato digital Adriana M. Cubides Peña, Ruddy A. Rivera Luque. Director: Dr. Oscar Luis Pyszczek. INCIDENCIA SOCIOECÓNOMICA DEL CULTIVO DE PALMA AFRICANA EN EL MUNICIPIO DE PUERTO GAITÁN- DEPARTAMENTO DEL META Y SU EVOLUCIÓN EN EL PERIÓDO (1991-2017). Revista Geográfica Digital. IGUNNE. Facultad de Humanidades. UNNE. Año 15. № 29. Enero - Junio 2018. ISSN 1668-5180 Resistencia, Chaco.

En: http://hum.unne.edu.ar/revistas/geoweb/default.htm 
Tabla 1 Matriz metodológica

\begin{tabular}{|c|c|c|}
\hline OBJETIVO ESPECÍFICO & TÉCNICA A UTILIZAR & $\begin{array}{l}\text { ACTIVIDADES A } \\
\text { DESARROLLAR PARA } \\
\text { EJECUTAR LA TÉCNICA }\end{array}$ \\
\hline $\begin{array}{l}\text { Analizar la evolución del } \\
\text { cultivo de palma en el } \\
\text { municipio de Puerto } \\
\text { Gaitán entre 1991-2017 }\end{array}$ & $\begin{array}{l}\text {-Análisis documental } \\
\text {-Análisis de imágenes } \\
\text { satelitales. } \\
\text {-Técnicas cartográficas }\end{array}$ & $\begin{array}{l}\text { - Contextualización de los cultivos } \\
\text { de palma } \\
\text {-Descripción, especificaciones, } \\
\text { procedencia y usos del cultivo de } \\
\text { palma. } \\
\text {-Obtención de imágenes } \\
\text { satelitales portal EarthExplorer } \\
\text { U.S.G.S. } \\
\text {-Selección de imágenes } \\
\text { satelitales Landsat. } \\
\text {-Procesamiento de imágenes } \\
\text { satelitales. } \\
\text {-Clasificación de los cultivos } \\
\text { mediante fotointerpretación. } \\
\text {-Cartografía de la evolución del } \\
\text { cultivo de palma periódo (1991- } \\
\text { 2017) }\end{array}$ \\
\hline $\begin{array}{l}\text { Determinar la influencia en } \\
\text { el desarrollo } \\
\text { socioeconómico que ha } \\
\text { tenido el cultivo de palma } \\
\text { en relación a la tenencia } \\
\text { de la tierra, Competencia } \\
\text { entre actividades } \\
\text { económicas y expansión } \\
\text { no planificada del } \\
\text { municipio en el periódo de } \\
\text { 1991-2017. }\end{array}$ & $\begin{array}{l}\text {-Encuestas sociales a } \\
\text { cultivadores, trabajadores y } \\
\text { población en general. } \\
\text {-Entrevistas } \\
\text { semiestructuradas. }\end{array}$ & $\begin{array}{l}\text {-Selección de las muestras. } \\
\text {-Elaboración de encuestas. } \\
\text {-Realización de pruebas pilotos } \\
\text { de las encuestas, trabajo de } \\
\text { campo. } \\
\text {-Entrevistas Alcaldía municipal, } \\
\text { Cenipalma, Aedepalma, } \\
\text { Plantas de beneficio. }\end{array}$ \\
\hline $\begin{array}{l}\text { Proponer líneas de acción } \\
\text { para la planificación del } \\
\text { cultivo de palma en el }\end{array}$ & $\begin{array}{l}\text {-Análisis } \\
\text { económico, } \\
\text { ambiental. }\end{array}$ & $\begin{array}{l}\text {-Diagnóstico municipal frente al } \\
\text { desarrollo de los cultivos de } \\
\text { palma. }\end{array}$ \\
\hline
\end{tabular}

Publicado en formato digital Adriana M. Cubides Peña, Ruddy A. Rivera Luque. Director: Dr. Oscar Luis Pyszczek. INCIDENCIA SOCIOECÓNOMICA DEL CULTIVO DE PALMA AFRICANA EN EL MUNICIPIO DE PUERTO GAITÁN- DEPARTAMENTO DEL META Y SU EVOLUCIÓN EN EL PERIÓDO (1991-2017). Revista Geográfica Digital. IGUNNE. Facultad de Humanidades. UNNE. Año 15. № 29. Enero - Junio 2018. ISSN 1668-5180 Resistencia, Chaco. 
Revista Geográfica Digital. IGUNNE. Facultad de Humanidades. UNNE. Año 15. № 29. Enero - Junio 2018. ISSN 1668-5180 Resistencia, Chaco

\begin{tabular}{|l|l|l|}
\hline $\begin{array}{l}\text { municipio de Puerto } \\
\text { Gaitán. }\end{array}$ & -Técnica cartográfica & $\begin{array}{l}\text {-implementación de estrategias } \\
\text { concernientes al cultivo de palma. }\end{array}$ \\
& -análisis multicriterio. \\
& -Propuesta cartográfica \\
\hline
\end{tabular}

\section{RESULTADOS}

La palma de aceite es una planta tropical propia de climas cálidos que crece en altitudes de 0 a $500 \mathrm{msnm}$. Su nombre científico es Elaeis guineensis Jac. Su origen se ubica en el golfo de Guinea en el África occidental, de allí que su denominación popular es palma africana de aceite. Su introducción a América se atribuye a los colonizadores y comerciantes de esclavos portugueses, que la usaban como parte de su dieta alimenticia. Clusius, en el año 1605 expuso que la palma se encontraba en la costa de Guinea y que el fruto, después de añadirle la harina de cierta raíz, era usado por los portugueses de San Thomé para alimentar a sus esclavos durante todo el viaje a América (García, 2006).

La palma africana necesita condiciones climáticas y de terreno (condiciones edafo- climáticas) muy específicas para una producción ideal: las zonas tropicales del mundo resultan ser particularmente apropiadas para su cultivo.

Tabla 2 Condiciones Edafoclimáticas

\begin{tabular}{|c|c|}
\hline Latitud & Entre $15^{\circ}$ de latitud Norte y $15^{\circ}$ de latitud Sur \\
\hline Altitud (msnm) & Hasta 500 mts. \\
\hline Terrenos & Con pendientes menores a $15^{\circ}$ \\
\hline Suelos & $\begin{array}{l}\text { Francos, franco-arcillosos planos o ligeramente } \\
\text { ondulados, sueltos y profundos de buena permeabilidad } \\
\text { y bien drenados, con } \mathrm{PH} \text { neutro o moderadamente ácido } \\
\text { (máx. } \mathrm{PH} 4 \text { ) }\end{array}$ \\
\hline Temperatura $\left({ }^{\circ} \mathrm{C}\right)$ & Máx. $33^{\circ}-$ Min. $22^{\circ}$. En todo caso no inferior a $21^{\circ}$ \\
\hline Luminosidad (Horas luz/año) & Superior a $1500 \mathrm{~h}$. \\
\hline Lluvia (mm/año) & $\begin{array}{l}\text { Entre } 1.800 \text { y } 2.200 \mathrm{~mm} \text {. Pero son suficientes hasta } \\
1.500 \mathrm{~mm} \text {. si hay lluvia todos los meses }\end{array}$ \\
\hline
\end{tabular}

Fuente: Federación Nacional de Cultivadores de Palma de Aceite (FEDEPALMA), FAO, entidades y empresas de palma de varios países, Human Rights Everywhere (HREV).

Una vez extraído, el aceite crudo es procesado para obtener dos productos: la oleína (líquida), que es utilizada casi exclusivamente como comestible y la estearina (sólida), cuya utilización principal es en la industria de cosméticos, jabones y detergentes. Entre las utilizaciones esperadas del aceite de palma, se tienen que indicar, por su posible importancia, las investigaciones sobre la posibilidad de utilizar este recurso en la producción de combustible (biodiesel) (Mingorance F., Minelli, F., \& Le Du, H., 2004).

Publicado en formato digital Adriana M. Cubides Peña, Ruddy A. Rivera Luque. Director: Dr. Oscar Luis Pyszczek. INCIDENCIA SOCIOECÓNOMICA DEL CULTIVO DE PALMA AFRICANA EN EL MUNICIPIO DE PUERTO GAITÁN- DEPARTAMENTO DEL META Y SU EVOLUCIÓN EN EL PERIÓDO (1991-2017). Revista Geográfica Digital. IGUNNE. Facultad de Humanidades. UNNE. Año 15. № 29. Enero - Junio 2018. ISSN 1668-5180 Resistencia, Chaco.

En: http://hum.unne.edu.ar/revistas/geoweb/default.htm 
El uso primario del aceite de palma se aplica a diversos productos comestibles: desde representar el principal ingrediente en aceites culinarios y margarinas, hasta ser utilizado en helados y confitería, en comidas listas para consumir, alimentos infantiles y otros. El aceite de palmiste se utiliza en la producción de jabones, champús, detergentes, artículos de tocador y cosméticos. Las estimaciones mundiales asignan el $80 \%$ del uso total del aceite de palma en el mundo a los productos comestibles, el $15 \%$ a los productos de cuidado personal y un $5 \%$ al agrodiesel. (FEDEPALMA, 2015).

Los cultivos de palma en el país se encuentran distribuidos principalmente en tres regiones (norte, central y oriental). En 2016 el área sembrada en palma de aceite fue de 512.076 hectáreas, de las cuales el $40 \%$ corresponde a la Zona Oriental, $32 \%$ a la Central, $24 \%$ a la Norte y en un ínfimo $4 \%$ a la Suroccidental. A su vez, del total sembrado con palma de aceite en Colombia, 113.029 hectáreas se encontraban en fase de desarrollo y 399.048 hectáreas estaban en producción, lo que muestra una composición del $22 \%$ en etapa improductiva y del $78 \%$ en etapa de producción.

Para el análisis evolutivo del cultivo de palma africana, fue necesario recopilar imágenes satelitales desde el año 1991 al 2017; dichas imágenes fueron descargadas de la página EarthExplorer U.S.G.S. Los años escogidos para el estudio fueron 1991, 2009 y 2017 derivados de las imágenes satelitales Landsat correspondientes para cada año.

Por medio de imágenes satelitales correspondientes a los periódos mencionados, se realizaron 4 salidas gráficas usando como herramienta el Software ArcGIS, con el objetivo de identificar cual ha sido la evolución de los cultivos de palma en el municipio de puerto Gaitán- Meta.

Para el año de 1991, en el municipio de Puerto Gaitán se evidenció una mínima área, representada por dos cultivos, el de mayor extensión perteneciente a la empresa extractora SAPUGA S.A conocida por ser la primera empresa en cultivar palma en el municipio; la de menor extensión por campesinos de la región. El área sembrada para este año correspondió a 1.605 Has. Es decir, menos de $16 \mathrm{~km}^{2}$.

Figura 2. Porcentaje del área sembrada por zonas-2016

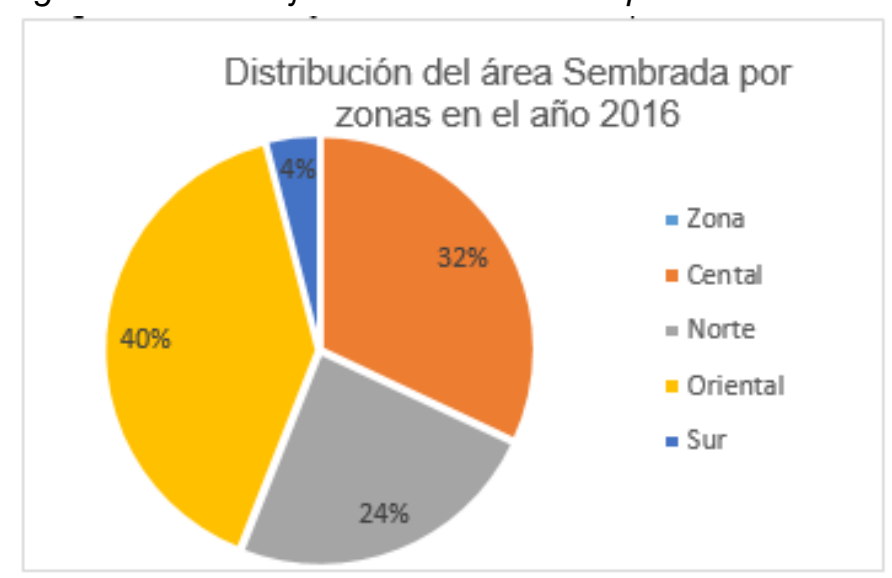

Fuente: Elaboración propia con base en zonas palmera Fedepalma

Publicado en formato digital Adriana M. Cubides Peña, Ruddy A. Rivera Luque. Director: Dr. Oscar Luis Pyszczek. INCIDENCIA SOCIOECÓNOMICA DEL CULTIVO DE PALMA AFRICANA EN EL MUNICIPIO DE PUERTO GAITÁN- DEPARTAMENTO DEL META Y SU EVOLUCIÓN EN EL PERIÓDO (1991-2017). Revista Geográfica Digital. IGUNNE. Facultad de Humanidades. UNNE. Año 15. № 29. Enero - Junio 2018. ISSN 1668-5180 Resistencia, Chaco. 
Con respecto al año 2009, la superficie sembrada de palma corresponde a 6.771 has, donde se evidencia que los cultivos ya establecidos en el periodo de 1991, tuvieron un incremento en el área sembrada, y posteriormente se generaron otros más a lo largo y ancho del departamento. Sin embargo, la extensión en superficie no representa un porcentaje significativo con respecto al área total del municipio, dado que para esta época la exploración y explotación de hidrocarburos es la actividad económica principal. Los kilómetros que representa el cultivo de palma para el año 2009 es de 67.9 km².

Para el año 2017, el municipio contaba con 26.972 has. distribuidas en 24 áreas de cultivos, se puede evidenciar que las primeras zonas establecidas aumentaron su tamaño considerablemente, advirtiéndose una evolución en los cultivos de palma en el municipio. El área de cultivo para el año 2017 es de $270.4 \mathrm{~km}^{2}$, lo que representa un 1.5\% de la superficie total del municipio de Puerto Gaitán.

Figura 3 Cultivos de palma 1991

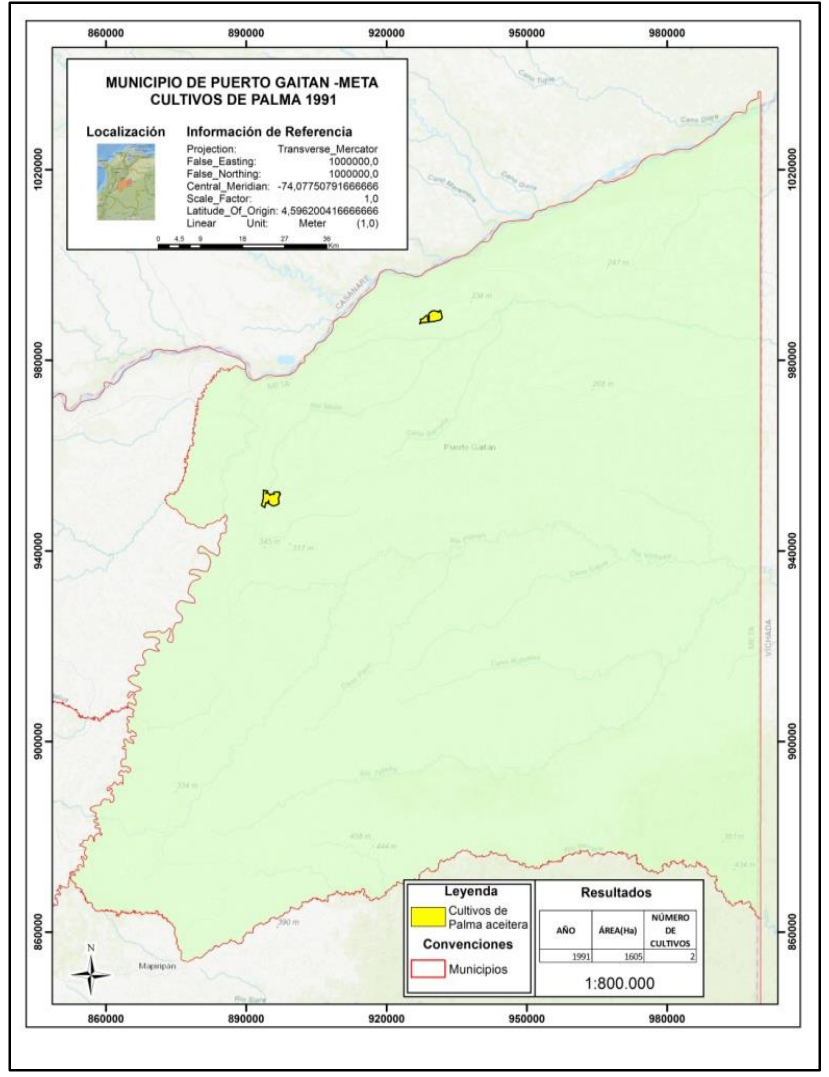

Figura 4 Cultivos de palma 2009

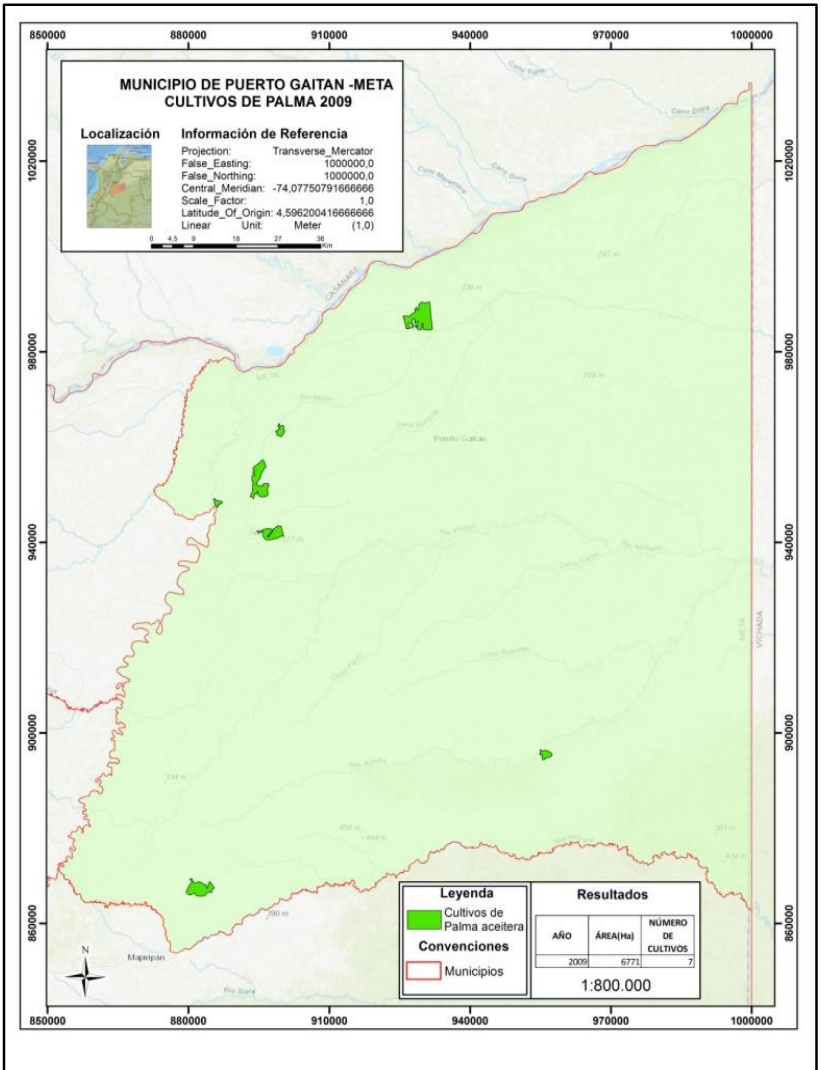

Publicado en formato digital Adriana M. Cubides Peña, Ruddy A. Rivera Luque. Director: Dr. Oscar Luis Pyszczek. INCIDENCIA SOCIOECÓNOMICA DEL CULTIVO DE PALMA AFRICANA EN EL MUNICIPIO DE PUERTO GAITÁN- DEPARTAMENTO DEL META Y SU EVOLUCIÓN EN EL PERIÓDO (1991-2017). Revista Geográfica Digital. IGUNNE. Facultad de Humanidades. UNNE. Año 15. № 29. Enero - Junio 2018. ISSN 1668-5180 Resistencia, Chaco.

En: http://hum.unne.edu.ar/revistas/geoweb/default.htm 
Revista Geográfica Digital. IGUNNE. Facultad de Humanidades. UNNE. Año 15. № 29

Figura 5. Cultivo de palma 2017

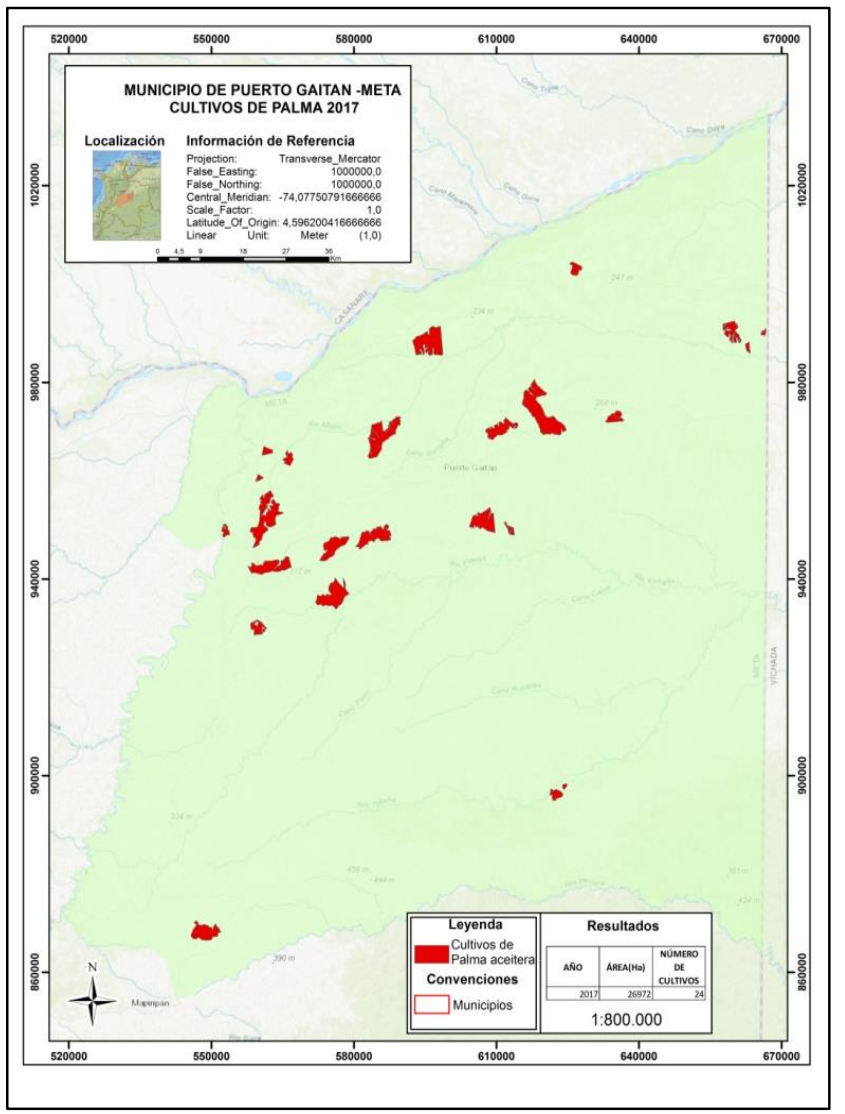

Figura 6. Cultivo de palma 1991-2009-2017

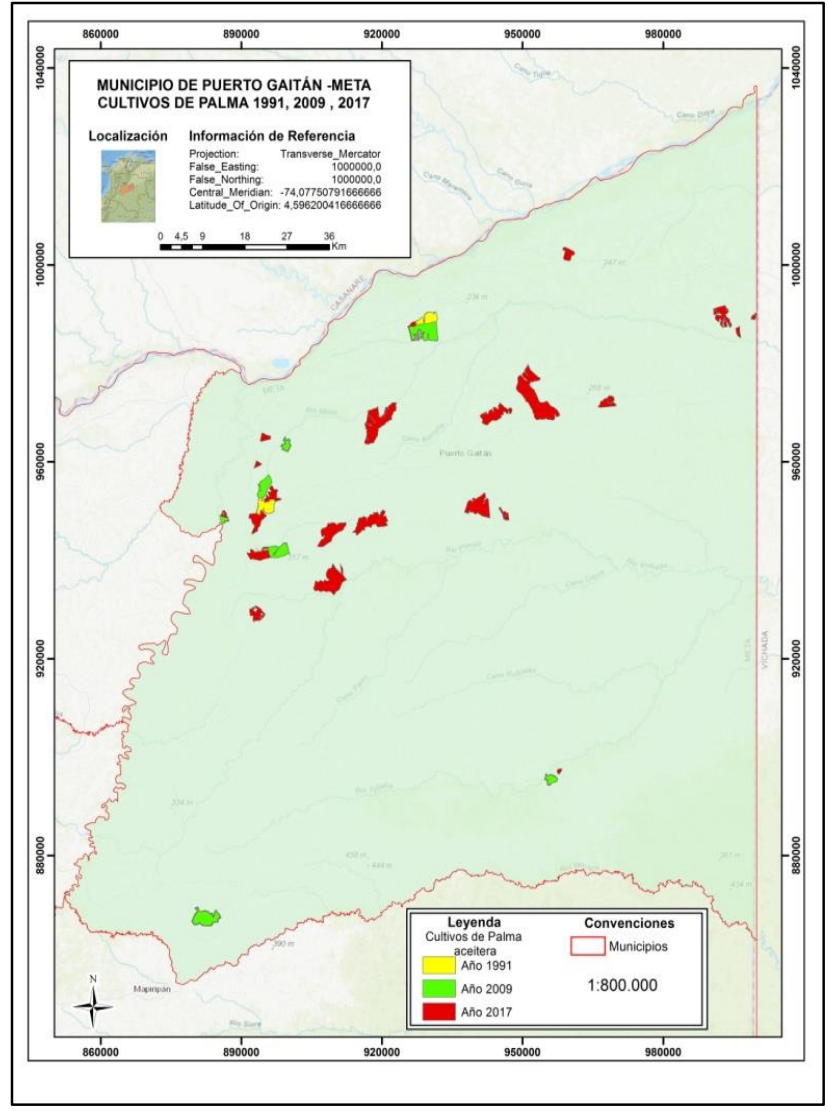

Fuente: Elaboración Propia.

Se puede distinguir el asentamiento de la palma en la zona norte del municipio con 21 áreas de cultivos y sobre la zona sur apenas con 3 áreas de cultivos. La zona norte refleja una mejor adaptabilidad de la palma debido a que posee mayores afluentes hídricos que en la zona contraria; siendo este un requisito central para el desarrollo del cultivo de palma aceitera.

Para efectos de la investigación, se utilizaron encuestas de percepción de la población en relación al cultivo de palma africana en el área de estudio, donde se tomaron 3 centros poblados del municipio y el casco urbano como referentes espaciales para la realización de las mismas. Para el casco urbano se determinó la mayor cantidad de encuestados siendo 20 en total, mientras que en los centros poblados La Cristalina, Puente Arimena y Planas se destinó para cada uno 10 encuestas. Los principales resultados de las encuestas de percepción, pueden observarse en las siguientes gráficas:

Publicado en formato digital Adriana M. Cubides Peña, Ruddy A. Rivera Luque. Director: Dr. Oscar Luis Pyszczek. INCIDENCIA SOCIOECÓNOMICA DEL CULTIVO DE PALMA AFRICANA EN EL MUNICIPIO DE PUERTO GAITÁN- DEPARTAMENTO DEL META Y SU EVOLUCIÓN EN EL PERIÓDO (1991-2017). Revista Geográfica Digital. IGUNNE. Facultad de Humanidades. UNNE. Año 15. № 29. Enero - Junio 2018. ISSN 1668-5180 Resistencia, Chaco.

En: http://hum.unne.edu.ar/revistas/geoweb/default.htm 
Revista Geográfica Digital. IGUNNE. Facultad de Humanidades. UNNE. Año 15. № 29.

Figura 7. Resultados encuestas de percepción.
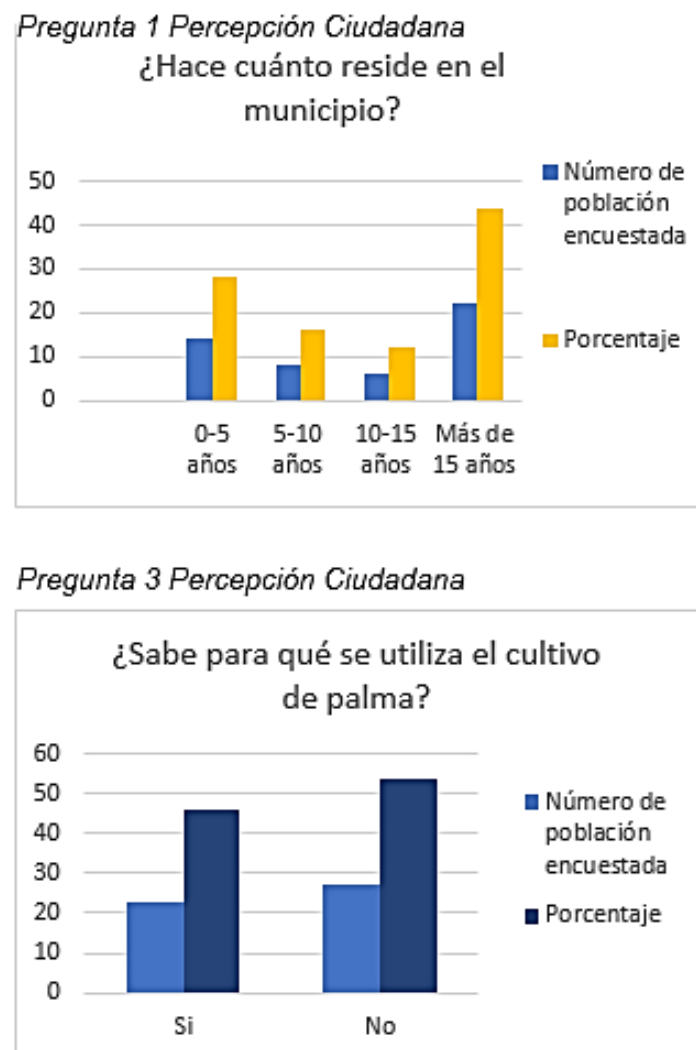

Fuente: Elaboración propia.

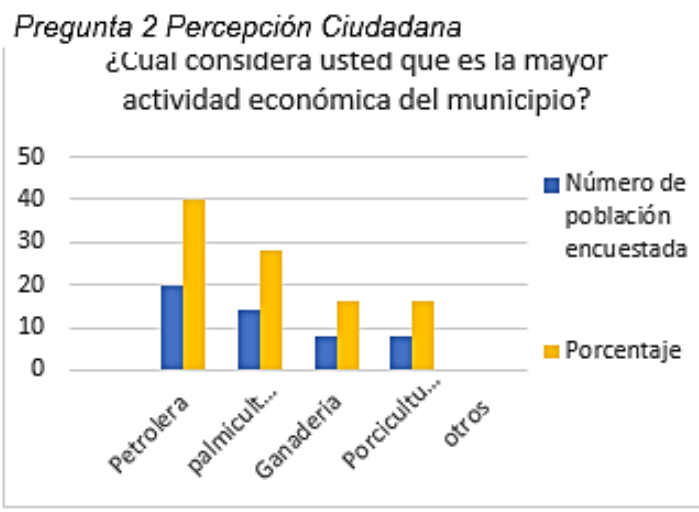

Pregunta 4 Percepción Ciudadana

¿Desde su perspectiva el cultivo de palma ha evolucionado en el municipio?

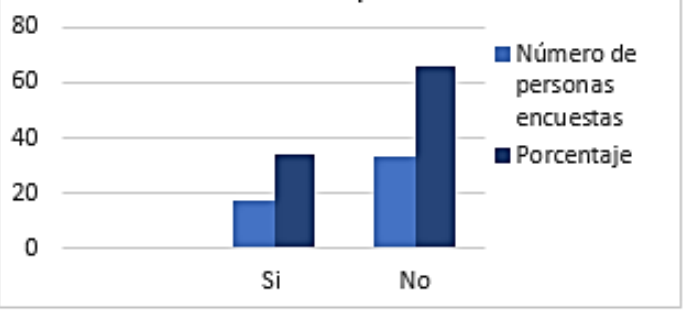

En la segunda pregunta se hallaron resultados muy diversos en la población: un condicionante de importancia ha sido el espacio en donde se encuestaba; para los centros poblados como lo son La Cristalina y Puente Arimena respondieron en su gran mayoría que la actividad económica era el cultivo de palma. Cabe resaltar que dichos centros poblados tienen una cercanía a la mayoría de cultivos de la región. Los resultados obtenidos mediante las encuestas han demostrado que, para la población del municipio de Puerto Gaitán, la actividad que mayor ingreso genera a la región es el petróleo (49\%), seguido de la palmicultura (14\%) y de la ganadería y porcicultura $(8 \%)$.

La cuarta pregunta de las encuestas se basa en la perspectiva que tiene la población respecto a la evolución del cultivo de palma africana en el municipio. El 66\% de la población asegura no haber visto una evolución del cultivo de palma en la región en relación a la superficie que abarca. Los cascos urbanos fueron el que mayor tendencia en este sentido han tenido.

Publicado en formato digital Adriana M. Cubides Peña, Ruddy A. Rivera Luque. Director: Dr. Oscar Luis Pyszczek. INCIDENCIA SOCIOECÓNOMICA DEL CULTIVO DE PALMA AFRICANA EN EL MUNICIPIO DE PUERTO GAITÁN- DEPARTAMENTO DEL META Y SU EVOLUCIÓN EN EL PERIÓDO (1991-2017). Revista Geográfica Digital. IGUNNE. Facultad de Humanidades. UNNE. Año 15. № 29. Enero - Junio 2018. ISSN 1668-5180 Resistencia, Chaco. 
El centro poblado La Cristalina evidencia mayor cantidad de respuestas afirmativas, debido a que este tiene una relación más estrecha con los demás centros poblados cercanos a los cultivos palmeros: El Tenampa y Santa Sofía.

Figura 8. Resultados encuestas de percepción.

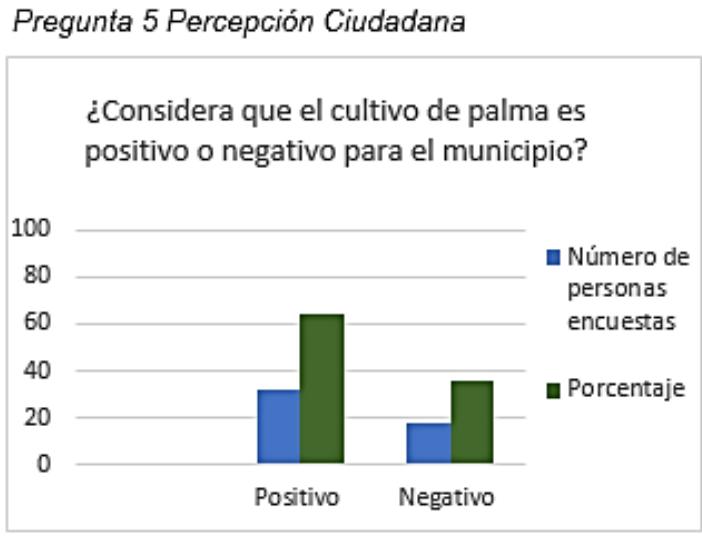

Pregunta 7 Percepción Ciudadana

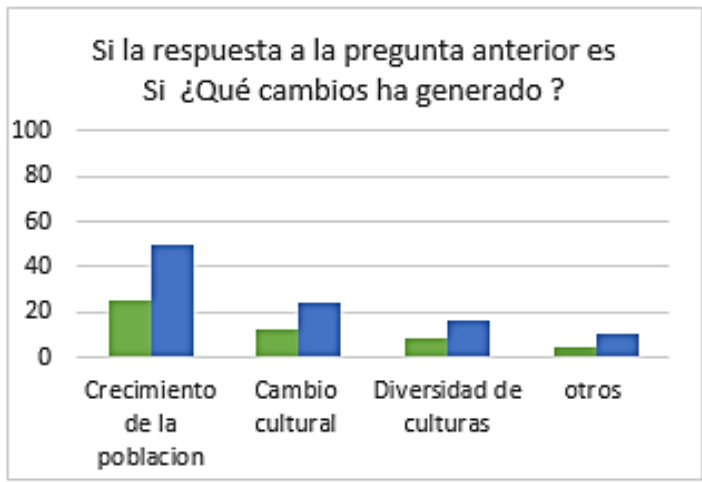

Fuente: Elaboración propia.
Pregunta 6 Percepción Ciudadana

¿Cree usted que los cultivos de palma han realizado un cambio en la parte social del municipio?

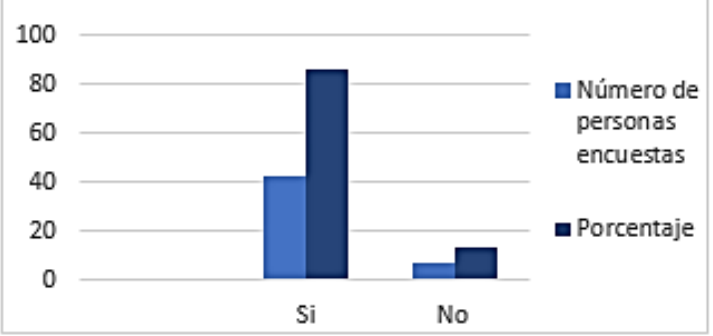

Pregunta 8 Percepción Ciudadana

En una escala del 1 al 5; donde 1 es bajo y 5 es alto ¿̇uánto representa para

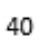
usted los cultivos de palma en la región?

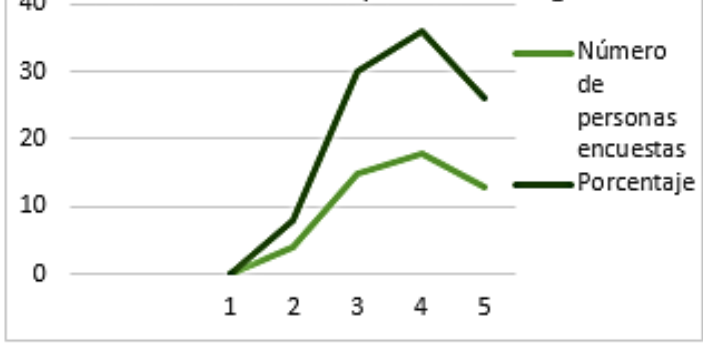

Respecto a la pregunta número 5, la población dio un visto bueno para el cultivo de palma africana. Entre las razones por la que dieron esta respuesta se encuentra mayor participación económica en las zonas encuestadas, es decir para los comerciantes de la región es más rentable los cultivos de palma que la explotación petrolera debido a que los contratos para dichos cultivos son de largo plazo. Para los centros poblados La cristalina, Planas y Puente Arimena es un sustento tanto económico como social pues genera puestos de empleo estables.

Respecto a la opinión de la comunidad, surge la pregunta de conocer si la llegada del cultivo de palma a la región ha significado un cambio en el aspecto social. Esta pregunta fue planteada principalmente por los impactos sociales que ha tenido, previamente, la explotación de petróleo,

Publicado en formato digital Adriana M. Cubides Peña, Ruddy A. Rivera Luque. Director: Dr. Oscar Luis Pyszczek. INCIDENCIA SOCIOECÓNOMICA DEL CULTIVO DE PALMA AFRICANA EN EL MUNICIPIO DE PUERTO GAITÁN- DEPARTAMENTO DEL META Y SU EVOLUCIÓN EN EL PERIÓDO (1991-2017). Revista Geográfica Digital. IGUNNE. Facultad de Humanidades. UNNE. Año 15. № 29. Enero - Junio 2018. ISSN 1668-5180 Resistencia, Chaco. 
Aunque la respuesta fue afirmativa en un $86 \%$ (pregunta 6), dichos cambios sociales no son negativos como lo hace entender la población encuestada. La pregunta ligada a este tema muestra que en su mayoría el crecimiento poblacional es el mayor cambio generado; esto se debe a la migración de familias enteras de otros departamentos de Colombia al municipio en busca de oportunidades de empleo en el sector palmero.

Por último, se encuentra la pregunta sobre la consideración de la población con respecto a la siembra de palma en el municipio, esta pregunta ayudó a entender cuan positivo o negativo era dicha siembra en la región. En su mayoría la población dio puntaje mayor oscilando entre 4 y 5 a los cultivos de palma aceitera; lo cual puede entenderse que la población está de acuerdo con los cultivos.

Las encuestas que registraron la opinión de las personas que trabajan directamente con los cultivos de palma o afines (como las extractoras), brindan la visión "desde dentro" de la actividad, dicha encuesta está estructurada por 6 preguntas, 3 preguntas abiertas y dos cerradas.

Se visitaron 4 áreas de siembra estratégicas y se desarrollaron un total de 50 encuestas distribuidas en Sapuga (cultivo con mayor antigüedad) se realizaron 20 encuestas, Santa Sofía El tenampa y Corocora se realizaron 10 para cada una. El porcentaje de encuestados por sexo significó que un $94 \%$ se realizaron a hombres y $6 \%$ restante a mujeres.

Figura 9. Cultivos de Palma visitados.

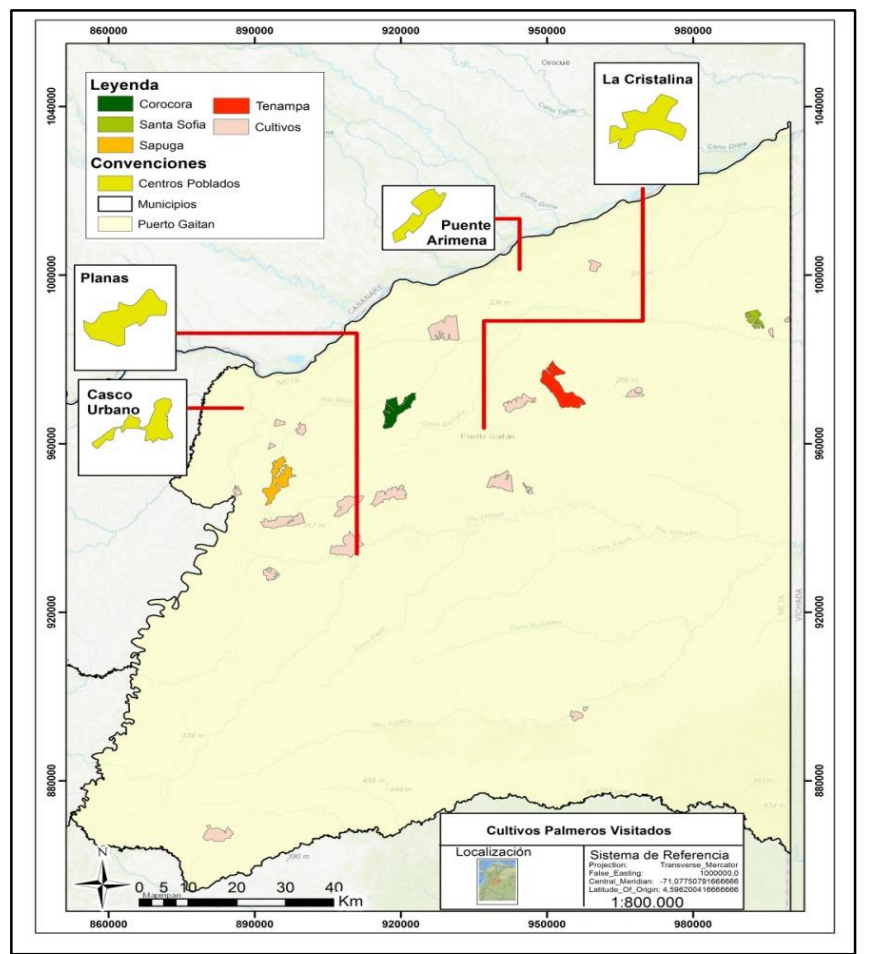

Fuente: Elaboración propia con base en información de la Alcaldía

Publicado en formato digital Adriana M. Cubides Peña, Ruddy A. Rivera Luque. Director: Dr. Oscar Luis Pyszczek. INCIDENCIA SOCIOECÓNOMICA DEL CULTIVO DE PALMA AFRICANA EN EL MUNICIPIO DE PUERTO GAITÁN- DEPARTAMENTO DEL META Y SU EVOLUCIÓN EN EL PERIÓDO (1991-2017). Revista Geográfica Digital. IGUNNE. Facultad de Humanidades. UNNE. Año 15. № 29. Enero - Junio 2018. ISSN 1668-5180 Resistencia, Chaco. 
Revista Geográfica Digital. IGUNNE. Facultad de Humanidades. UNNE. Año 15. № 29.

Enero - Junio 2018. ISSN 1668-5180 Resistencia, Chaco

Figura 10. Resultados encuestas.
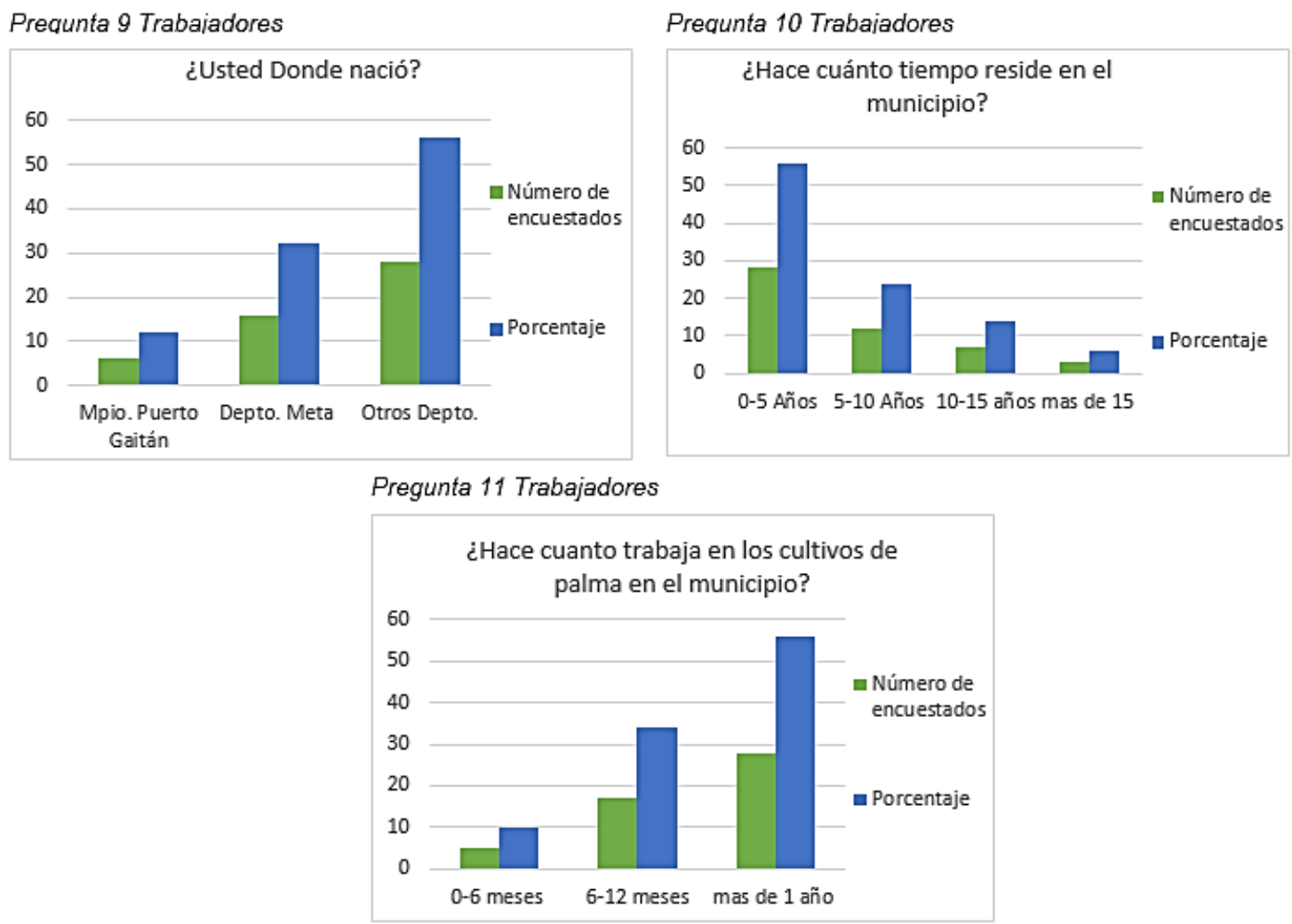

Fuente: Elaboración Propia.

De acuerdo con la investigación, en la población del municipio se encontró que existía mayor empleo para trabajadores foráneos a la región. Ante esto se decidió constatar dicha información con una pregunta acerca de donde provenían los trabajadores. La pregunta número 9 se realizó de forma abierta, sintetizándose aquellos que son del municipio de Puerto Gaitán, aquellos que son pertenecientes al departamento del Meta pero no al municipio de Puerto Gaitán y por último, aquellos provenientes de otros departamentos diferentes al Meta. Como resultado se obtuvo que en su mayoría, los trabajadores vienen de otros departamentos y la población local que realmente trabaja en los cultivos es ínfima.

Con respecto a lo antes mencionado, se consultó a los trabajadores hace cuánto tiempo residían en el municipio y a pesar de ser en su mayoría gente foránea se pudo evidenciar que llevan muchos años residiendo en el municipio. La mayoría de ellos llegaron en un principio a la región por empleos que consiguieron en la actividad petrolera, no obstante el auge petrolero en la región disminuyó considerablemente y generó el aumento de las tasas de desempleo. Debido a estas circunstancias, muchos trabajadores empezaron a buscar otros rubros laborales para dedicarse,

Publicado en formato digital Adriana M. Cubides Peña, Ruddy A. Rivera Luque. Director: Dr. Oscar Luis Pyszczek. INCIDENCIA SOCIOECÓNOMICA DEL CULTIVO DE PALMA AFRICANA EN EL MUNICIPIO DE PUERTO GAITÁN- DEPARTAMENTO DEL META Y SU EVOLUCIÓN EN EL PERIÓDO (1991-2017). Revista Geográfica Digital. IGUNNE. Facultad de Humanidades. UNNE. Año 15. № 29. Enero - Junio 2018. ISSN 1668-5180 Resistencia, Chaco.

En: http://hum.unne.edu.ar/revistas/geoweb/default.htm 
Revista Geográfica Digital. IGUNNE. Facultad de Humanidades. UNNE. Año 15. № 29.

Enero - Junio 2018. ISSN 1668-5180 Resistencia, Chaco

entre ellos la actividad agrícola palmera, en el Gráfico 16, se muestra los meses que los trabajadores llevan laborando en los cultivos de palma: el 56\% lleva más de un año trabajando con los cultivos de palma, y un 34\% más de 6 meses.es decir esta actividad tiene mayor porcentaje de estabilidad a la que se plantea con la extracción de hidrocarburos. Cabe resaltar que aquellos que llevan más de un año trabajando en el cultivo de palma dentro del municipio; han pasado por diferentes cultivos, pero aseguran que se sienten más seguros trabajando en el sector palmero que en el petrolero. Esto nos lleva a preguntarnos sobre ¿qué beneficios les ha traído a los trabajadores vincularse con esta parte del sector agropecuario?

Algunos de los trabajadores aseguran que la estabilidad económica es lo más importante, y trabajando para dicho sector la tienen. El crecimiento profesional también ha sido manifestado en el relevamiento. Para la mayoría de los encuestados, el trabajo con la agricultura, especialmente de cultivos de larga duración como lo son la palma, el caucho, entre otros, es la solución social y económica que necesita un municipio.

Por último, se hizo mención a los aspectos positivos y negativos que trae aparejado el cultivo de palma respecto al municipio en general. Entre los aspectos más destacados fueron los positivos como la generación de empleo y oportunidades, el beneficio directo al comercio, la valorización de la finca raíz y el crecimiento poblacional. Por otra parte, dentro los aspectos negativos el más destacado por los encuestados ha sido la poca participación en trabajos palmeros de la población procedente del municipio.

Simultáneamente, y a fin de profundizar los resultados obtenidos mediante las encuestas, se han realizado entrevistas semiestructuradas a diferentes actores sociales relacionados con el cultivo de palma africana. Para la ejecución de las entrevistas se contemplaron preguntas concretas y otras que surgían durante su desarrollo y pueden apreciarse en la Tabla $\mathrm{N}^{\circ} 3$ :

Tabla 3 Entrevistas

\begin{tabular}{|l|l|l|l|l|}
\hline \multirow{2}{*}{ Nombre } & \multirow{2}{*}{$\begin{array}{l}\text { Ocupación } \\
\text { sector }\end{array}$} & \multicolumn{2}{|l|}{ Respuestas destacadas } \\
\cline { 3 - 5 } & Tenencia de la tierra & $\begin{array}{l}\text { Competencia entre } \\
\text { actividades } \\
\text { económicas (palma, } \\
\text { petróleo) }\end{array}$ & $\begin{array}{l}\text { Expansión no } \\
\text { planificada }\end{array}$ \\
\hline $\begin{array}{l}\text { Leonardo } \\
\text { Restrepo } \\
\text { terranova }\end{array}$ & $\begin{array}{l}\text { Secretario } \\
\text { agropecuario } \\
\text { y medio } \\
\text { ambiente./ } \\
\begin{array}{l}\text { Alcaldía } \\
\text { municipal }\end{array}\end{array}$ & $\begin{array}{l}\text {-existen cultivos } \\
\text { pequeños de palma } \\
\text { promocionados por los } \\
\text { campesinos de la región }\end{array}$ & $\begin{array}{l}\text {-el cultivo de palma } \\
\text { será una fuente } \\
\text { económica potencial } \\
\text { para el municipio. }\end{array}$ & $\begin{array}{l}\text {-la secretaría } \\
\text { implementa } \\
\text { proyectos para todo } \\
\text { tipo de cultivos } \\
\text { permanentes, mas } \\
\text { sin embargo no se } \\
\text { ha establecido } \\
\text { acerca de la } \\
\text { planeación de la } \\
\text { palma. }\end{array}$ \\
& $\begin{array}{l}\text { como lo son promotora } \\
\text { palmas de Puerto Gaitán } \\
\text { tienen como } \\
\text { inversionistas a los } \\
\text { campesinos dueños de la } \\
\text { tierra. }\end{array}$ & $\begin{array}{l}\text {-el petróleo generó } \\
\text { problemas sociales } \\
\text { durante su auge. }\end{array}$ & $\begin{array}{l}\text {-los cultivos } \\
\text { permanentes son } \\
\text { propicios para el }\end{array}$ & $\begin{array}{l}\text {-se tiene en cuenta } \\
\text { alrededor de las }\end{array}$ \\
\hline
\end{tabular}

Publicado en formato digital Adriana M. Cubides Peña, Ruddy A. Rivera Luque. Director: Dr. Oscar Luis Pyszczek. INCIDENCIA SOCIOECÓNOMICA DEL CULTIVO DE PALMA AFRICANA EN EL MUNICIPIO DE PUERTO GAITÁN- DEPARTAMENTO DEL META Y SU EVOLUCIÓN EN EL PERIÓDO (1991-2017). Revista Geográfica Digital. IGUNNE. Facultad de Humanidades. UNNE. Año 15. № 29. Enero - Junio 2018. ISSN 1668-5180 Resistencia, Chaco. 
Revista Geográfica Digital. IGUNNE. Facultad de Humanidades. UNNE. Año 15. № 29.

Enero - Junio 2018. ISSN 1668-5180 Resistencia, Chaco

\begin{tabular}{|c|c|c|c|c|}
\hline & & & $\begin{array}{l}\text { desarrollo de los } \\
\text { municipios. }\end{array}$ & $\begin{array}{l}\text { hectáreas que se } \\
\text { han plantado en el } \\
\text { municipio. }\end{array}$ \\
\hline $\begin{array}{l}\text { Leonardo } \\
\text { Garzón }\end{array}$ & $\begin{array}{l}\text { Jefe oficina } \\
\text { de } \\
\text { planeación / } \\
\text { Alcaldía } \\
\text { municipal }\end{array}$ & $\begin{array}{l}\text {-los campesinos de la } \\
\text { región han optado por } \\
\text { implantar cultivos } \\
\text { transitorios debido al } \\
\text { costo de la siembra de los } \\
\text { cultivos de palma, aunque } \\
\text { si se ha evidenciado que } \\
\text { algunos han logrado } \\
\text { apoyo del gobierno y } \\
\text { empresas palmeras en la } \\
\text { región. }\end{array}$ & $\begin{array}{l}\text {-El petróleo en la } \\
\text { región será siempre la } \\
\text { mayor actividad } \\
\text { económica del } \\
\text { municipio. } \\
\text {-los sueldos por parte } \\
\text { de las empresas } \\
\text { petroleras son } \\
\text { mayores a las } \\
\text { empresas y cultivos } \\
\text { palmeros. }\end{array}$ & $\begin{array}{l}\text {-No existe ningún } \\
\text { tipo de programa, } \\
\text { proyecto o plan } \\
\text { vinculado a la } \\
\text { expansión del } \\
\text { cultivo de palma. }\end{array}$ \\
\hline \begin{tabular}{|l|} 
Cipriano \\
Ulloa
\end{tabular} & $\begin{array}{l}\text { Jefe planta } \\
\text { extractora } \\
\text { Abago S.A.S }\end{array}$ & $\begin{array}{l}\text {-aquellos campesinos que } \\
\text { han decidido vender sus } \\
\text { tierras para los cultivos de } \\
\text { palma, han podido invertir } \\
\text { tanto dentro como fuera } \\
\text { de la región. }\end{array}$ & $\begin{array}{l}\text {-el futuro del municipio } \\
\text { está en el cultivo de } \\
\text { palma, el cual genera } \\
\text { mayor empleo y } \\
\text { estabilidad económica. } \\
\text {-el municipio ha } \\
\text { cambiado } \\
\text { positivamente desde el } \\
\text { ingreso de los cultivos } \\
\text { de palma a la región, } \\
\text { las poblaciones } \\
\text { cercanas a los cultivos } \\
\text { han evidenciado un } \\
\text { ingreso económico } \\
\text { mayor al sector } \\
\text { petrolero. }\end{array}$ & $\begin{array}{l}\text {-se podría decir } \\
\text { que si existe una } \\
\text { expansión no } \\
\text { planificada de los } \\
\text { cultivos de palma } \\
\text { debido a que en } \\
\text { pocos años } \\
\text { empezó a ascender } \\
\text { de manera } \\
\text { exponencial las } \\
\text { plantaciones. }\end{array}$ \\
\hline $\begin{array}{l}\text { Ricardo } \\
\text { García }\end{array}$ & $\begin{array}{l}\text { Jefe planta } \\
\text { extractora } \\
\text { San } \\
\text { Sebastiano }\end{array}$ & $\begin{array}{l}\text {-en el municipio no se } \\
\text { evidencia un cambio } \\
\text { abrupto por la venta de } \\
\text { terreno para la plantación } \\
\text { de palma. , en mi opinión } \\
\text { es un beneficio mutuo } \\
\text { debido a que las tierras } \\
\text { vendidas son a un } \\
\text { razonable precio. }\end{array}$ & $\begin{array}{l}\text {-el aporte de empleos } \\
\text { directos que genera } \\
\text { las palmeras no se } \\
\text { compara con los } \\
\text { pocos trabajadores } \\
\text { que ahora necesita las } \\
\text { empresas petroleras; } \\
\text { sin contar los empleos } \\
\text { indirectos y las } \\
\text { ganancias que se } \\
\text { obtiene cuando } \\
\text { existen extractoras de } \\
\text { fruto en el municipio }\end{array}$ & $\begin{array}{l}\text {-la alcaldía } \\
\text { municipal no ha } \\
\text { empezado a } \\
\text { realizar tácticas } \\
\text { para el sector } \\
\text { palmero, lo cual a } \\
\text { futuro generara } \\
\text { deficiencias como } \\
\text { se evidencia en } \\
\text { otros municipios de } \\
\text { Colombia. }\end{array}$ \\
\hline
\end{tabular}

Publicado en formato digital Adriana M. Cubides Peña, Ruddy A. Rivera Luque. Director: Dr. Oscar Luis Pyszczek. INCIDENCIA SOCIOECÓNOMICA DEL CULTIVO DE PALMA AFRICANA EN EL MUNICIPIO DE PUERTO GAITÁN- DEPARTAMENTO DEL META Y SU EVOLUCIÓN EN EL PERIÓDO (1991-2017). Revista Geográfica Digital. IGUNNE. Facultad de Humanidades. UNNE. Año 15. № 29. Enero - Junio 2018. ISSN 1668-5180 Resistencia, Chaco. 
Revista Geográfica Digital. IGUNNE. Facultad de Humanidades. UNNE. Año 15. № 29.

Enero - Junio 2018. ISSN 1668-5180 Resistencia, Chaco

\begin{tabular}{|c|c|c|c|c|}
\hline & & & $\begin{array}{l}\text { debido a dichos } \\
\text { cultivos. }\end{array}$ & \\
\hline $\begin{array}{l}\text { Luis } \\
\text { Fernando } \\
\text { Cabrera }\end{array}$ & $\begin{array}{l}\text { Junta } \\
\text { directiva/ } \\
\text { Fedepalma }\end{array}$ & $\begin{array}{l}\text {-la tierra tiende a subir de } \\
\text { precio cuando se destina } \\
\text { para el cultivo de palma, } \\
\text { esto genera mayor } \\
\text { ingreso económico a } \\
\text { aquellos vendedores de } \\
\text { tierra como lo son los } \\
\text { campesinos. } \\
\text {-En Fedepalma se trata } \\
\text { sobre la participación de } \\
\text { los campesinos en los } \\
\text { municipios mediante } \\
\text { estrategias económicas } \\
\text { que ayuden al } \\
\text { campesinado a cultivar } \\
\text { palma en sus fincas, } \\
\text { Puerto Gaitán no es la } \\
\text { excepción se tienen datos } \\
\text { sobre pequeños cultivos } \\
\text { de palma que han sido } \\
\text { generado por campesinos } \\
\text { mediante Fedepalma }\end{array}$ & $\begin{array}{l}\text {-los cultivos de palma } \\
\text { han podido acceder a } \\
\text { zonas donde ha } \\
\text { prevalecido la } \\
\text { explotación petrolera, } \\
\text { siendo la palma un } \\
\text { cambio económico y } \\
\text { social positivo para la } \\
\text { región. }\end{array}$ & $\begin{array}{l}\text {-Puerto Gaitán ha } \\
\text { sido un municipio } \\
\text { donde se puede } \\
\text { denotar los } \\
\text { cambios } \\
\text { representativos de } \\
\text { la palma frente a } \\
\text { otros municipios de } \\
\text { Colombia. Aunque } \\
\text { actualmente no } \\
\text { cuenta con planes } \\
\text { relacionados al } \\
\text { cultivo, el municipio } \\
\text { ha logrado } \\
\text { mantener una } \\
\text { eficiencia en la } \\
\text { producción de } \\
\text { aceite. }\end{array}$ \\
\hline $\begin{array}{l}\text { Valentina } \\
\text { Arango }\end{array}$ & $\begin{array}{l}\text { Grupo de } \\
\text { investigación } \\
\text { / Cenipalma }\end{array}$ & $\begin{array}{l}\text { De los datos vinculados a } \\
\text { Cenipalma no se tiene } \\
\text { ningún registro a fin sobre } \\
\text { un desplazamiento no } \\
\text { forzado del campesinado } \\
\text { del municipio. }\end{array}$ & $\begin{array}{l}\text {-los cultivos de palma } \\
\text { tienen un mayor } \\
\text { aporte a cualquier } \\
\text { región que se } \\
\text { implemente }\end{array}$ & \\
\hline
\end{tabular}

Para realizar la triangulación metodológica basados en las encuestas realizadas (percepción ciudadana, trabajadores), entrevistas generadas (alcaldía, Fedepalma, Cenipalma, extractoras) y las observaciones realizadas en la visita a campo. Se tomaron en cuenta aquellas preguntas relacionadas entre sí, referidas a los cultivos de Palma. La primera pregunta fue ¿Considera que el cultivo de palma es una fuente importante de ingreso económico en el municipio?, para el primer sector, es decir las encuestas (percepción ciudadana, trabajadores) la opinión recabada fue siempre positiva. Más sin embargo en las entrevistas realizadas, especialmente a la alcaldía, se evidenció que el cultivo genera ingresos, pero aun no los suficientes. Por su parte, en las observaciones realizadas pudimos advertir cierta tendencia en el predominio de la explotación de hidrocarburos, como principal fuente de ingresos por parte de la población y la alcaldía. No obstante, hay indicios que el cultivo de palma ha generado ciertos cambios en el pensamiento y planificación económica del municipio.

La segunda pregunta correlacionada se refiere a ¿Qué ha generado el cultivo de palma en el municipio? Para la alcaldía municipal al igual que las plantas extractoras, el cultivo ha generado

Publicado en formato digital Adriana M. Cubides Peña, Ruddy A. Rivera Luque. Director: Dr. Oscar Luis Pyszczek. INCIDENCIA SOCIOECÓNOMICA DEL CULTIVO DE PALMA AFRICANA EN EL MUNICIPIO DE PUERTO GAITÁN- DEPARTAMENTO DEL META Y SU EVOLUCIÓN EN EL PERIÓDO (1991-2017). Revista Geográfica Digital. IGUNNE. Facultad de Humanidades. UNNE. Año 15. № 29. Enero - Junio 2018. ISSN 1668-5180 Resistencia, Chaco. 
Revista Geográfica Digital. IGUNNE. Facultad de Humanidades. UNNE. Año 15. № 29.

Enero - Junio 2018. ISSN 1668-5180 Resistencia, Chaco

impactos sociales, fundamentalmente con la llegada de personal foráneo a la región; enriqueciendo el factor cultural del municipio. La población encuestada (Percepción ciudadana) difiere de que este aspecto sea positivo para los habitantes nacidos en Puerto Gaitán. Esta pregunta tiene relación con la competencia económica entre la palma y el petróleo, lo cual se planteó en la siguiente pregunta ¿Considera usted que el cultivo de palma generará mayor ingreso e impacto social al municipio? las observaciones que se tomaron en cuenta en el momento de realizar las entrevistas y encuestas evidenció que para la población en general, la actividad económica petrolera no genera agrado en la parte social. La alcaldía local estuvo de acuerdo que el impacto social gira en torno a la llegada de personas foráneas y que esta inmigración no ha sido tan considerable como lo había sido años anteriores respecto al petróleo. Los centros poblados encuestados han relacionado el cultivo de palma como el mejor instrumento para que el municipio crezca en los aspectos económicos, sociales y ambientales en contraposición a la extracción de petróleo.

Otra pegunta que se tomó en cuenta especialmente para las entidades entrevistadas fue ¿desde su perspectiva: el cultivo de palma ha evolucionado en el municipio? En las entrevistas se pudo evidenciar que el cultivo de palma se empezó a expandir sin ninguna restricción dentro del municipio, en un lapso de tiempo inferior a 8 años. La población a su vez dio certeza de ello, debido a que el personal encuestado como comerciantes relacionó un cambio en los ingresos, desde que se incrementó el cultivo de palma. Mediante las observaciones en las empresas palmeras visitadas se pudo constatar que muy pocas hectáreas tenían cultivos de palma de más de 10 años; el resto tenía una antigüedad de inferior a los 7 años.

Los cultivos de palma han presentado gran dinámica, y cada día tienen más presencia en el área de estudio, ganando protagonismo en el ámbito nacional y territorial, generando cuestionamientos positivos y negativos. Sin embargo, sigue siendo de gran importancia la implementación de estos cultivos dada la demanda que tiene gracias a su versatilidad y múltiples usos comestibles y no comestibles.

En el municipio de Puerto Gaitán, la extracción de hidrocarburos ha definido el rumbo económico, social y ambiental, siendo una actividad de gran importancia. No obstante, la expansión de las actividades agrícolas, como es el caso de la palma, se convierten en un nodo diferente para el desarrollo económico y social que requieren lineamientos que permitan un desarrollo sostenible, a fin de generar una orientación y organización de la actividad palmicultora de forma coherente. En este orden de ideas se proponen 3 estrategias, seguidas por líneas de acción a realizar en un plazo inmediato a fin desarrollar una actividad agrícola coherente y cohesionada.

1. Por medio de la primera estrategia llamada Aptitud del suelo, se propusieron dos líneas de acción, donde se establecen zonas específicas y adecuadas para la expansión de cultivos existentes y la implementación de nuevas áreas de siembra, evitando así una expansión no planificada de los mismos. De igual manera se controla la deforestación y cualquier afectación a los ecosistemas al establecer los cultivos en zonas de frontera agrícola, teniendo en cuenta condiciones como la radiación solar y la precipitación que permiten un mejor desarrollo del cultivo.

2. Debido al importante papel que cumple la población dentro del desarrollo de los cultivos de palma, se plantean dos líneas de acción. La primera permitirá a la población perteneciente al

Publicado en formato digital Adriana M. Cubides Peña, Ruddy A. Rivera Luque. Director: Dr. Oscar Luis Pyszczek. INCIDENCIA SOCIOECÓNOMICA DEL CULTIVO DE PALMA AFRICANA EN EL MUNICIPIO DE PUERTO GAITÁN- DEPARTAMENTO DEL META Y SU EVOLUCIÓN EN EL PERIÓDO (1991-2017). Revista Geográfica Digital. IGUNNE. Facultad de Humanidades. UNNE. Año 15. № 29. Enero - Junio 2018. ISSN 1668-5180 Resistencia, Chaco.

En: http://hum.unne.edu.ar/revistas/geoweb/default.htm 
municipio acceder de forma prioritaria, a los diferentes empleos que ofrece el sector palmero. De este modo se mejorará la calidad de vida de la población. Por otro lado, se plantean espacios de aprendizaje que permitan a la población relacionada con el sector palmero, un mayor conocimiento de prácticas sostenibles por medio de la educación agrícola.

3. La organización de los pequeños y medianos palmicultores permitirá mayor eficiencia en sus actividades, dado que las economías de escala son fundamentales para reducir los costos de extracción de aceite, y para el crecimiento de los núcleos palmeros mejorando su competitividad

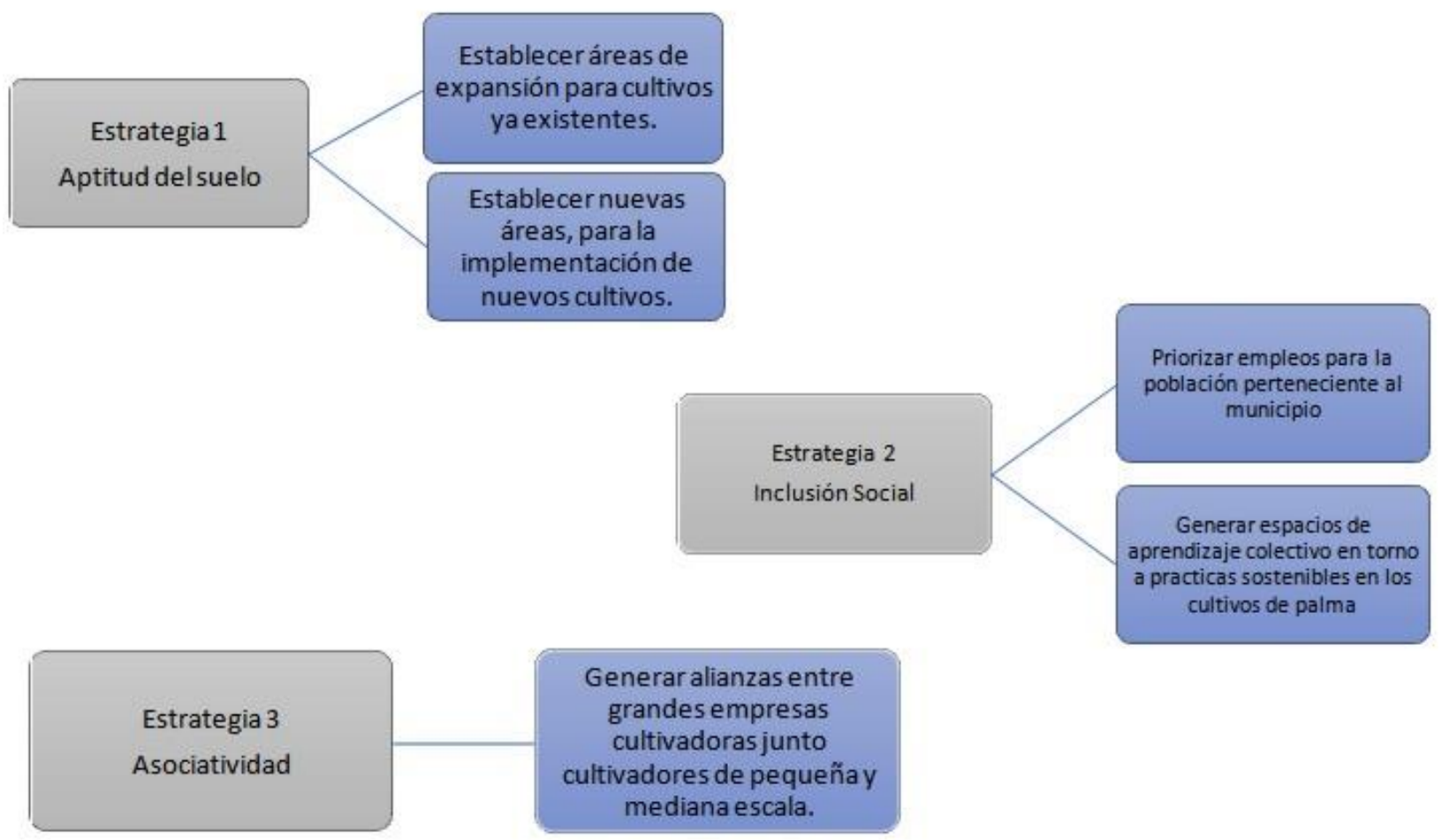

Con base en las estrategias propuestas, se tuvieron en cuenta algunos criterios para lograr una aproximación cartográfica de la primera estrategia: aptitud del suelo, la cual se vincularía con la estrategia número 3 teniendo en cuenta que dependiendo de las zonas aptas para la implementación del cultivo de palma se generarán asociatividades entre pequeños y grandes productores para la expansión de esta misma. Los siguientes mapas son la base para implementar las áreas de expansión de los cultivos ya existentes y las áreas para la implementación de nuevos cultivos.

El método utilizado para realizar la propuesta cartográfica ha sido mediante el software Arcmap y la herramienta de Arctool box -weigth overlay (pesos ponderados), las variables a tener en cuenta son el mapa de litología, cobertura de la tierra, pendientes, radiación solar anual y

Publicado en formato digital Adriana M. Cubides Peña, Ruddy A. Rivera Luque. Director: Dr. Oscar Luis Pyszczek. INCIDENCIA SOCIOECÓNOMICA DEL CULTIVO DE PALMA AFRICANA EN EL MUNICIPIO DE PUERTO GAITÁN- DEPARTAMENTO DEL META Y SU EVOLUCIÓN EN EL PERIÓDO (1991-2017). Revista Geográfica Digital. IGUNNE. Facultad de Humanidades. UNNE. Año 15. № 29. Enero - Junio 2018. ISSN 1668-5180 Resistencia, Chaco. 
precipitación anual. Estas variables fueron escogidas luego de acabado el análisis de la información recolectada referente a los factores más importantes para cultivar palma.

Figura 11. Cobertura del suelo.
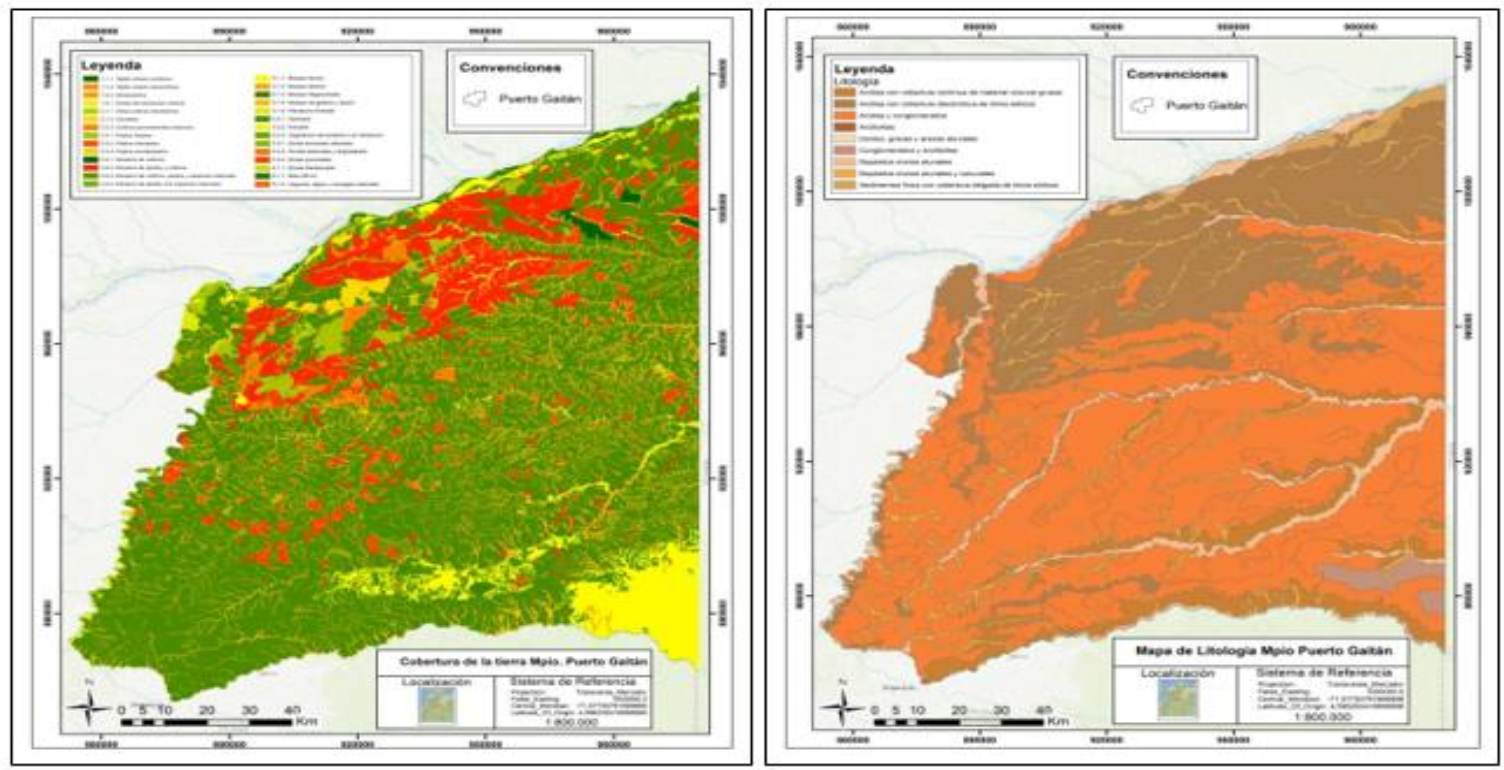

Figura 12. Radiación solar y Precipitación anual.
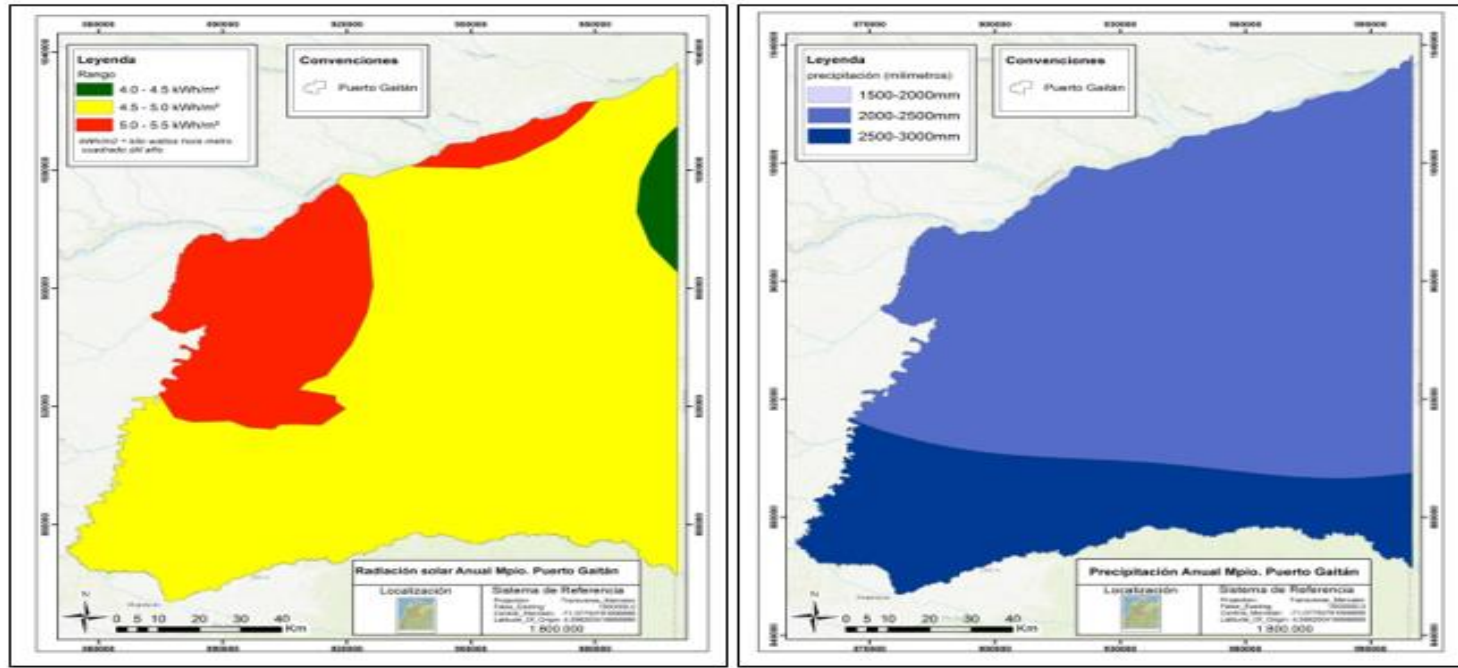

Fuente: Elaboración Propia.

Publicado en formato digital Adriana M. Cubides Peña, Ruddy A. Rivera Luque. Director: Dr. Oscar Luis Pyszczek. INCIDENCIA SOCIOECÓNOMICA DEL CULTIVO DE PALMA AFRICANA EN EL MUNICIPIO DE PUERTO GAITÁN- DEPARTAMENTO DEL META Y SU EVOLUCIÓN EN EL PERIÓDO (1991-2017). Revista Geográfica Digital. IGUNNE. Facultad de Humanidades. UNNE. Año 15. № 29. Enero - Junio 2018. ISSN 1668-5180 Resistencia, Chaco.

En: http://hum.unne.edu.ar/revistas/geoweb/default.htm 
Tomando como base los criterios mencionados anteriormente, y la selección de las áreas óptimas de expansión y de establecimiento de nuevos cultivos, se establecieron zonas de asociatividad, dado que la fortaleza productiva de la palma es fundamental para su sostenibilidad económica. Muchas de las soluciones a los problemas que enfrenta esta agroindustria están relacionadas con los avances en materia de productividad, al igual que en materia de buenas prácticas agrícolas y empresariales, razón por la cual es indispensable generar espacios que permitan la asociatividad en esta actividad productiva. Si bien en muchos casos los cultivos de palma de aceite han sido desarrollado por grandes grupos empresariales, dentro del municipio los agricultores de pequeña y mediana escala también están presentes frente a lo cual es muy importante la organización de los productores para lograr mejores rendimientos que permitan avanzar mucho más en el sector palmero.

Figura 13. Propuesta de Planificación.
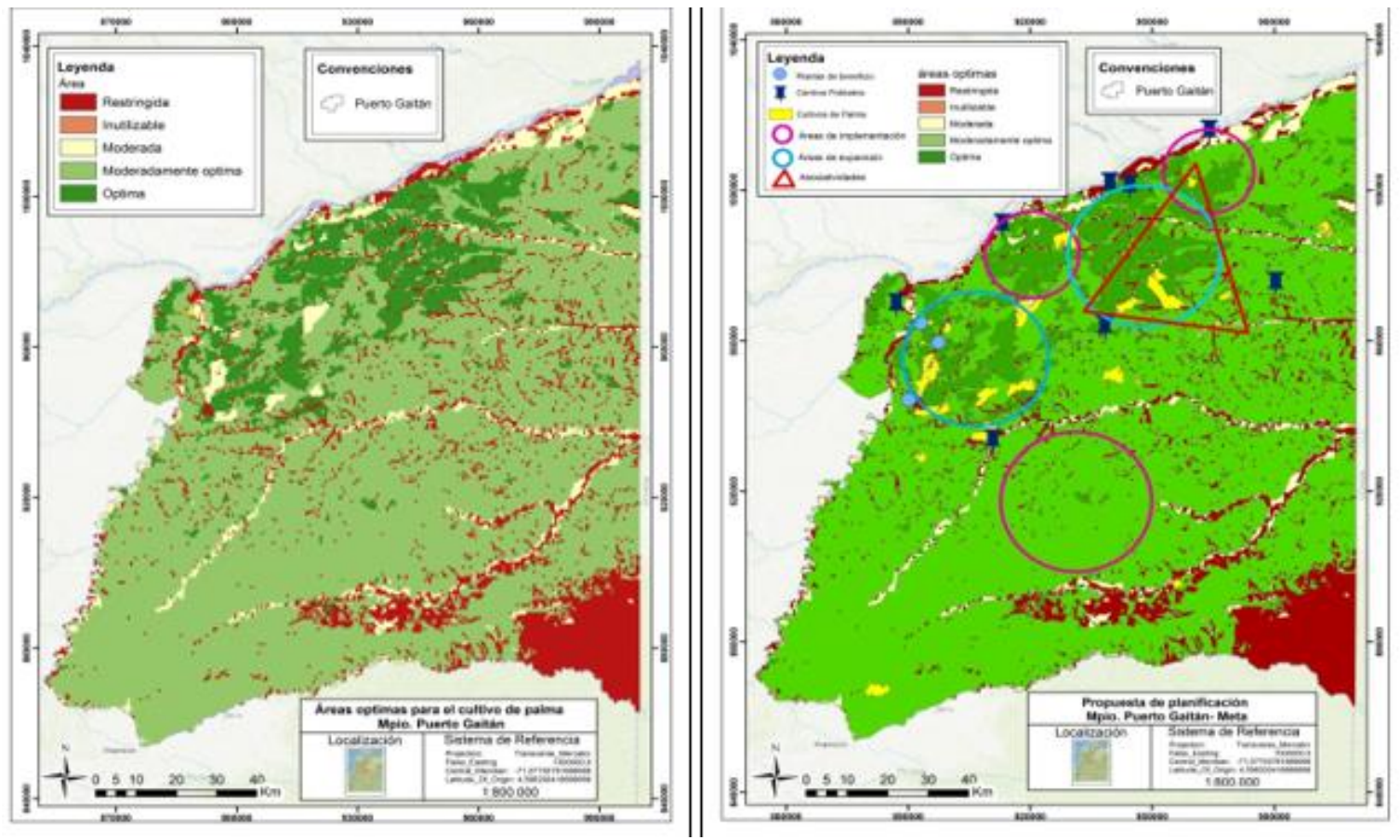

Fuente: Elaboración Propia.

\section{CONCLUSIONES Y RECOMENDACIONES}

-Aunque a lo largo de la historia los cultivos de palma han generado serios impactos negativos al ambiente, el municipio de puerto Gaitán no ha transformado sus ecosistemas a diferencia de otras zonas del país.

Publicado en formato digital Adriana M. Cubides Peña, Ruddy A. Rivera Luque. Director: Dr. Oscar Luis Pyszczek. INCIDENCIA SOCIOECÓNOMICA DEL CULTIVO DE PALMA AFRICANA EN EL MUNICIPIO DE PUERTO GAITÁN- DEPARTAMENTO DEL META Y SU EVOLUCIÓN EN EL PERIÓDO (1991-2017). Revista Geográfica Digital. IGUNNE. Facultad de Humanidades. UNNE. Año 15. № 29. Enero - Junio 2018. ISSN 1668-5180 Resistencia, Chaco.

En: http://hum.unne.edu.ar/revistas/geoweb/default.htm 
-Los cultivos de palma han evolucionado en el país, hasta el punto de convertirse en uno de los elementos agrícolas más importantes para la economía colombiana, generando oportunidad de empleo en zonas apartadas del país.

-El municipio de Puerto Gaitán, posee un conjunto de características óptimas para el desarrollo de actividades agrícolas, situación que permite ir cambiando las actividades extractivas por actividades de tipo rural.

-Las actividades económicas del municipio como la extracción de hidrocarburos y el cultivo de palma, generan un decrecimiento y crecimiento en la población dependiendo de las ofertas laborales.

-El desarrollo o mejoramiento de los cultivos de palma no se encuentran presentes dentro de ningún plan programa o proyecto actual del municipio.

-Dentro del actual plan de desarrollo del municipio los cultivos de palma no cuentan con una óptima participación para la mejora de dicha práctica.

-El desarrollo de la actividad palmera en el municipio tiene que realizarse bajo un control de responsabilidad ambiental y social, a través de buenos modelos y permanente acompañamiento. - La asociatividad es otro aspecto fundamental en esta actividad productiva. Si bien en muchos casos los cultivos de palma de aceite han sido desarrollado por grandes grupos empresariales, la inclusión de los agricultores de pequeña y mediana escala es fundamental para el crecimiento y desarrollo de la actividad palmera.

-Se requiere pronta actualización de la información catastral del municipio, puesto que es una herramienta clave para la toma de decisiones con respecto al uso y tenencia de la tierra en el municipio, a fin de optimizar la planificación territorial.

-Aunque los cultivos de palma permiten la entrada de nueva población al municipio, los oriundos del lugar sienten pérdida de identidad del municipio.

-Las siembras de palma de aceite pueden adelantarse sin deforestar y dentro de la frontera agrícola, dada la gran extensión de tierra cultivable en el país.

- La palma de aceite puede tener amplios beneficios sociales en las zonas rurales. En el caso de Puerto Gaitán, hay más formalidad, los empleos son de mejor calidad comparados con los ofrecidos por otras actividades rurales.

\section{REFERENCIAS}

-AFRICANA, C. 2015. Panorama sobre el sector de palma africana Conferencia Mundial del sector Palma Africana IUF

\section{-ALCALDÍA DE PUERTO GAITÁN 2016. Puerto Gaitán-Meta Voluntad para el progreso}

2016-2019, Plan de desarrollo.

-EOT 2012 Esquema de ordenamiento. Municipio de Puerto Gaitán-Colombia.

-INFOAGRO Palma africana aceitera coroto de guinea. Sistema de Información agropecuario colombiano.

Publicado en formato digital Adriana M. Cubides Peña, Ruddy A. Rivera Luque. Director: Dr. Oscar Luis Pyszczek. INCIDENCIA SOCIOECÓNOMICA DEL CULTIVO DE PALMA AFRICANA EN EL MUNICIPIO DE PUERTO GAITÁN- DEPARTAMENTO DEL META Y SU EVOLUCIÓN EN EL PERIÓDO (1991-2017). Revista Geográfica Digital. IGUNNE. Facultad de Humanidades. UNNE. Año 15. № 29. Enero - Junio 2018. ISSN 1668-5180 Resistencia, Chaco. 
-GARCIA L 2006 Generalidades de la Palma. Universidad Juárez Autónoma de Tabasco, División Académica de Ciencias Agropecuarias

-MINGORANCE F., MINELLI, F., \& Le Du, H. 2004. El cultivo de la palma africana en el Chocó: legalidad ambiental, territorial y derechos humanos. Colombia: Human Rights Everywhere. Códice. Bogotá Colombia.

Publicado en formato digital Adriana M. Cubides Peña, Ruddy A. Rivera Luque. Director: Dr. Oscar Luis Pyszczek. INCIDENCIA SOCIOECÓNOMICA DEL CULTIVO DE PALMA AFRICANA EN EL MUNICIPIO DE PUERTO GAITÁN- DEPARTAMENTO DEL META Y SU EVOLUCIÓN EN EL PERIÓDO (1991-2017). Revista Geográfica Digital. IGUNNE. Facultad de Humanidades. UNNE. Año 15. № 29. Enero - Junio 2018. ISSN 1668-5180 Resistencia, Chaco.

En: http://hum.unne.edu.ar/revistas/geoweb/default.htm 